\title{
RANCANG BANGUN SISTEM INFORMASI PENGGAJIAN KARYAWAN HARIAN LEPAS PADA PT FLEX INDONESIA
}

\author{
Nur Azizah ${ }^{1}$ \\ Lina Yuliana ${ }^{2}$ \\ Elsa Juliana ${ }^{3}$ \\ Dosen STMIK Raharja Informatika ${ }^{1}$ \\ STMIK Raharja Jurusan Sistem Informasi ${ }^{2,3}$ \\ Jl. Jendral Sudirman No. 40, Modernland, Tangerang ${ }^{1,2,3}$ \\ E-mail:nur.azizah@ raharja.info ${ }^{\text {l, }}$ lina.yuliana@raharja.info, ${ }^{2}$ elsa.juliana@raharja.info ${ }^{3,}$
}

\begin{abstract}
ABSTRAK
Pemanfaatan teknologi informasi pada ini telah berkembang pesat di segala bidang kehidupan manusia. Salah satunya adalah pemanfaatan komputer di bidang usaha. Program komputer yang telah banyak dikembangkan memudahkan manejemen dalam mengambil keputusan secara cepat, tepat dan akurat.Seperti halnya pada perhitungan penggajian karywan harian lepas pada PT Flex Indonesia yang dalam perhitungan gaji mempunyai permasalahan dalam sistem penggajian karyawan harian lepas yang masih menggunakan secara manual, yaitu menggunakan Microsoft Excel sehingga sering terjadi kesalahan dalam perhitungan penggajian dan proses pengerjaannya pun membutuhkan waktu yang cukup lama.Untuk memperoleh data yang diperlukan selama penelitian penulis menggunakan beberapa metode antara lain observasi, wawancara, dan studi pustaka dengan metode analisa menggunakan analisa SWOT yaitu kekuatan (strength) dan kelemahan (Weakness), peluang (opportunities) dan ancaman (treats). Kemudian sistem dirancang dengan menggunakan bahasa pemograman PHP, database yang digunakan adalah MySQL dengan menggunakan Tools UML (unified Modelling Language) dengan software Visual Paradigm 6.4, user interfacemenggunakan Adobe DreamweaverCS6.Model pengujian pada program ini menggunakan black box testing. Dengan demikian hasil penelitian ini adalah berupa rancangan sistem informasi penggajian yang dapat bermanfaat bagi PT Flex Indonesia baik sebagai untuk mengambil suatu keputusan.
\end{abstract}

Kata Kunci : Sistem Informasi, Penggajian PT Flex Indonesia.

\begin{abstract}
The utilization of information technology has been developing rapidly in all areas of human life. One is the use of computers in the business field. The computer program has been developed to facilitate the management to make decisions quickly and accurately. As in the calculation of payroll employees' casual at the PT Flex Indonesia which in the calculation of salaries have problems in the system of payroll casual that still use manually, using Microsoft Excel so that frequent errors in payroll calculation and workmanship also need quite a long time, To obtain the data needed for the study author uses several methods such as observation, interviews, and literature with an analysis method using SWOT analysis, namely strength (strength) and weakness (Weakness), opportunities (opportunities) and threats (treats). Then the system was designed using the programming language PHP, the database used is MySQL by using the Tools UML (Unified Modeling Language) with Visual Paradigm 6.4 software, user interface using Adobe DreamweaverCS6. Model testing on this program using black box testing. Therefore, the outcome of this study is to plan payroll information system that can be useful for Flex Indonesia PT well as to take a decision.
\end{abstract}

Keywords: Information Systems, Payroll PT Flex Indonesia. 


\section{PENDAHULUAN}

Teknologi yang berkembang menjadi sarana yang sangat mendukung untuk menangani berbagai permasalahan yang timbul dalam mengelola dan menyelesaikan pemasalahan yang ada diperusahaan, instansi maupun organisasi lain. Kebutuhan akan suatu sistem informasi telah mencakup hampir di segala ruang lingkup kehidupan. Membangun suatu sistem informasi memerlukan pemahaman yang baik dan jelas mengenai sistem yang akan digunakan baik dalam prosedur sistem, input, output maupun hal-hal yang mempengaruhi kinerja sistem baik untuk jangka pendek maupun jangka panjang. Oleh karena itu, pada kesempatan ini penulis melakukan penelitian mengenai sistem penggajian karyawan harian lepas yang berjalan pada PT Flex Indonesia.

PT Flex Indonesia adalah salah asatu perusahaan Garment Manfacturer yang terletak di J1 Industri VI Blok 1 No 5,6,7 Tangerang. Dimana sistem informasi penggajian karyawan harian lepas ini masih banyak data yang tidak terkelola dengan baik karena sistem penyimpanan data masih berupa pengarsipan, sehingga seringkali terjadi berkas hilang atau rusak secara fisik. Khususnya dalam menyusun laporan Penggajian karyawan harian lepas pada PT Flex Indonesia yaitu belum adanya sistem input data laporan penggajian berbasis $w e b$. Oleh karena itu dengan adanya sistem komputerisasi berbasis web, segala kebutuhan yang dikerjakan PT Flex Indonesia akan berjalan lebih cepat, tepat, dan akurat.

\section{PERMASALAHAN}

Berdasarkan latar belakang dan berdasarkan pengamatan yang dilakukan antara lain Adanya permasalahan dalam proses pengembangan pengolahan penggajian karyawan harian lepas pada PT Flex Indonesia, maka rumusan masalah penelitian ini adalah "Bagaimana merancang sistem informasi perhitungan gaji karyawan harian lepas pada PT. Flex Indonesia?"

\section{LITERATURE REVIEW}

1. Penelitian yang telah dijalankan oleh Sri Indah Sari (2011) ${ }^{[5]}$ berjudul "Perancangan Sistem Informasi Penggajian Guru Pada Madrasah Aliyah Al-hasaniyah Tangerang Berbasis Web".Sistem yang berjalan saat ini dalam hal penggajian masih manual dimana belum terdapatnya aplikasi program dan database yang menunjang dalam hal penggajian, sehingga tingkat kesalahan dalam mengolah data masih sangat besar. Pengembangan sistem yang penulis lakukan adalah agar sistem yang berlaku selama ini dapat dioptimalkan kinerjanya sehingga tidak ada lagi kesalahan-kesalahan yang mungkin terjadi dalam pengolahan data.

2. Penelitian yang dijalankan oleh Aropah (2011) ${ }^{[1]}$ dengan judul "Rancangan Sistem Penggajian Pegawai Honorer Pada SMP NEGERI 2 Gunung Sindur Dengan Metode Berorientasi Object", metode perancangan yang digunakan dalam penelitian ini adalah Unified Modelling Language (UML) dan untuk pembuatan sistem menggunakan Pemograman Java.

3. Penelitian yang dijalankan oleh Chindy Marchelina (2012) ${ }^{[3]}$,SMP Negeri MaukTangerang. Penelitiannya berjudul "Perancangan Sistem Informasi Penggajian Guru Pada SMP Negeri 1 Mauk-Tangerang". Sistem yang berjalan saat ini dalam hal penggajian guru masih bersifat manual, sehingga sering terjadi kesalahan dalam perhitungan gaji guru.

4. Penelitian yang dijalankan oleh Budhi Hartantyo (2012) ${ }^{[2]}$,PT Sury UtamaNusaparka Semarang berjudul "Sistem Informasi Penggajian Karyawan Pada PT.Surya Utama Nusaparka Semarang", metode perancangan yang digunakan dalam penelitian ini adalah 
normalisai dengan menggunakan alat bantu (Tools) berupa Microsoft Visual Basic 6.0 untuk pembuatan sistem ini menggunakan ERD dan DBMS (Database Management Sistem) sebagai databasenya.

5. Penelitian yang dijalankan oleh Elvi Selviana (2013) ${ }^{[4]}$, Kelurahan Cikokol Tangerang berjudul "Perancangan Sistem Informasi Penggajian Pegawai Berbasis web pada Kelurahan Cikokol Tangerang". Sistem penggajian pegawai yang berjalan saat ini masih menggunakan Ms.Access sehingga masih Belum optimal karena cara absensi pegawai masih secara manual

\section{LANDASAN TEORI}

\section{Definisi Sistem}

Sistem (system) dapat didefiniskan dengan pendekatan prosedur dan dengan pendekatan komponen.Dengan pendekatan prosedur, sistem dapat didefinisikan sebagai kumpulan dari prosedur-prosedur yang mempunyai tujuan tertentu.

Menurut Sugiarti (2011:99), $)^{[6]}$ "sistem merupakan suatu bentuk integrasi antara satu komponen dengan komponen lain karena sistem memiliki sasaran yang berbeda untuk setiap kasus yang terjadi dalam sistem tersebut".

\section{Konsep Dasar Informasi}

Sumber informasi adalah data. Data merupakan bentuk jamak dari bentuk tunggal data atau item. Menurut McLeod dalam buku yang ditulis oleh Yakub (Yakub, 2012:5) ${ }^{[8]}$, "Data adalah deskripsi kenyataan yang menggambarkan adanya suatu kejadian (event), data terdiri dari fakta $(f a c t)$ dan angka yang secara relatif tidak berarti bagi pemakai". Data dapat berbentuk nilai yang terformat, teks, citra, audio, dan video.

1. Teks, adalah sederetan huruf, angka, dan simbol-simbol yang kombinasinya tidak tergantung pada masing masing item secara individual. Misalnya, artikel koran, majalah dan lain-lain .

2. Data yang terformat, adalah data dengan suatu format tertentu, misalnya data yang menyatakan tanggal atau jam, dan nilai mata uang .

3. Citra (image), adalah data dalam bentuk gambar, citra dapat berupa, grafik, foto, hasil rontgen, dan tanda tangan .

4. Audio, adalah data dalam bentuk suara. Misalnya, instrumen musik, suara orang, suara binatang, detak jantung, dan lain-lain .

5. Video, adalah data dalam bentuk gambar yang bergerak dan dilengkapi dengan suara.Misalnya, suatu kejadian dan aktivitas-aktivitas dalam bentuk film.

\section{Kualitas Informasi}

Kualitas suatu informasi tergantung dari 3 hal, yaitu informasi harus akurat, tepat waktu, dan relevan. Penjelasan tentang kualitas informasi tersebut dipaparkan di bawah ini menurut Tata sutabri $(2012: 43)^{[7]}$ :

1. Akurat (Accurate) Informasi harus bebas dari kesalahan -kesalahan dan tidak menyesatkan. Akurat juga berarti informasi harus jelas mencerminkan maksudnya. Informasi harus akurat karena biasanya dari sumber informasi sampai penerima informasi ada kemungkinan terjadi gangguan yang dapat mengubah atau merusak informasi tersebut. 
2. Tepat Waktu (Timelines), Informasi yang datang pada si penerima tidak boleh terlambat. Informasi yang sudah usung tidak akan mempunyai nilai lagi karena informasi merupakan suatu landasan dalam pengambilan keputusan. Bila pengambilan keputusan terlambat maka dapat berakibat fatal bagi organisasi.

3. Relevan (Relevance) Informasi tersebut mempunyai manfaat untuk pemakainya, dimana relevansi informasi untuk tiap - tiap individu berbeda tergantung pada yang menerima dan yang membutuhkan. Nilai informasi ditentukan oleh dua hal yaitu manfaat dan biaya. Suatu informasi dikatakan bernilai apabila manfaatnya lebih efektif dibandingkan dengan biaya mendapatkannya.

\section{Nilai Informasi}

Suatu informasi dikatakan bernilai bila informasi lebih efektif dibandingkan dengan biaya mendapatkannya. Kegunaan informasi adalah untuk mengurangi hal ketidakpastian didalam proses pengambilan keputusan tentang suatu keadaan. Nilai dari informasi ditentukan dari dua hal yaitu manfaat dan biaya mendapatkannya. Akan tetapi perlu diperhatikan bahwa informasi yang digunakan di dalam suatu sistem informasi umumnya digunakan untuk beberapa kegunaan. Pengukuran suatu nilai informasi biasanya dihubungkan dengan Analysis Cost Effectiveness atau Cost Benefit. Adapun 10 (sepuluh) sifat yang dapat menentukan nilai informasi yaitu sebagai berikut:

1. Kemudahan dalam Memperoleh (Accesibility), Informasi memiliki nilai yang lebih sempurna apabila dapat diperoleh secara mudah. Informasi yang penting dan sangat dibutuhkan menjadi tidak bernilai jika sulit diperoleh.

2. Sifat Luas dan Kelengkapannya (Comprehensiveness) Informasi mempunyai nilai yang lebih sempurna apabila mempunyai lingkup atau cakupan yang luas dan lengkap. Informasi sepotong dan tidak lengkap menjadi tidak bernilai, karena tidak dapat digunakan secara baik.

3. Ketelitian (Accuracy) Informasi mempunyai nilai yang lebih sempurna apabila mempunyai ketelitian yang tinggi. Informasi menjadi tidak bernilai jika tidak akurat karena akan mengakibatkan kesalahan pengambilan keputusan.

4. Kecocokan dengan Pengguna (Relevance) Informasi mempunyai nilai yang lebih sempurna apabila sesuai dengan kebutuhan penggunanya. Informasi berharga dan penting menjadi tidak bernilai jika tidak sesuai dengan kebutuhan penggunanya karena tidak dapat dimanfaatkan untuk pengambilan keputusan.

5. Ketepatan Waktu (Timelines) Informasi mempunyai nilai yang lebih sempurna apabila dapat diterima oleh pengguna pada saat yang tepat. Informasi berharga dan penting menjadi tidak bernilai jika terlambat diterima atau usang, karena tidak dapat dimanfaatkan pada saat pengambilan keputusan.

6. Kejelasan (Clarity) Informasi yang jelas akan meningkatkan kesempurnaan nilai informasi. Kejelasan informasi dipengaruhi oleh bentuk danformat informasi.

7. Fleksibilitas (Flexibility) Nilai informasi semakin sempurna apabila memiliki fleksibilitas tinggi. Fleksibilitas informasi diperlukan oleh para manager atau pimpinan pada saat pengambilan keputusan.

8. Dapat Dibuktikan (Verified) Nilai informasi semakin sempurna apabila informasi tersebut dapat dibuktikan kebenarannya.Tidak Ada Prasangka (Unprejudiced) Nilai informasi semakin sempurna apabila informasi tersebut tidak menimbulkan prasangka dan keraguan adanya kesalahan informasi.

9. Dapat Diukur (Measurable) Informasi untuk pengambilan keputusan seharusnya dapat diukur agar dapat mencapai nilai yang sempurna. 


\section{PEMBAHASAN}

Metode yang digunakan dalam perancangan system informasi penggajian karyawan harian lepas adalah menggunakan metode berorientasi objek atau dikenal dengan Object Oriented Analysis and Design (OOAD). Sedangkan tool perancangan yang digunakan adalah Unified Modelling Language (UML) yang berarti bahasa pemodelan standar, UML memiliki sintaks dan semantik. Ketika kita membuat model menggunakan konsep UML ada aturan aturan yang harus diikuti.

\section{Use Case Diagram}

Use case diagram merupakan fungsionalitas yang diharapkan dari sebuah sistem. Yang ditekankan adalah "apa" yang diperbuat oleh sistem, bukan "bagaimana" sebuah sistem berjalan. Sebuah use case mempresentasikan sebuah interaksi antara actor dan sistem.

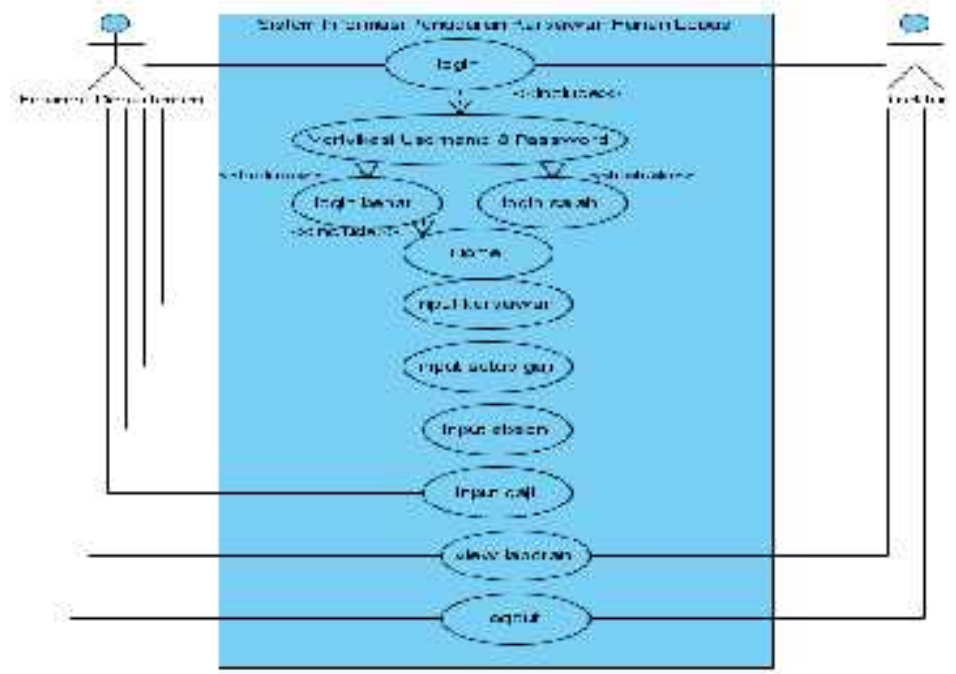

Gambar 1. Use Case Diagram

Berdasarkan gambar diatas, Use Case diagram terdapat:

a. 1 sistem yang mencakup seluruh kegiatan dalam proses penginputan.

b. 2 actor yang melakukan kegiatan yaitu bagian Finance Departement.

c. 8 use case yang akan dilakukan oleh aktor tersebut, seperti login, home, input karyawan HL, input setup gaji, input absen, input gaji,logout.

\section{Rancangan Tampilan Sistem}

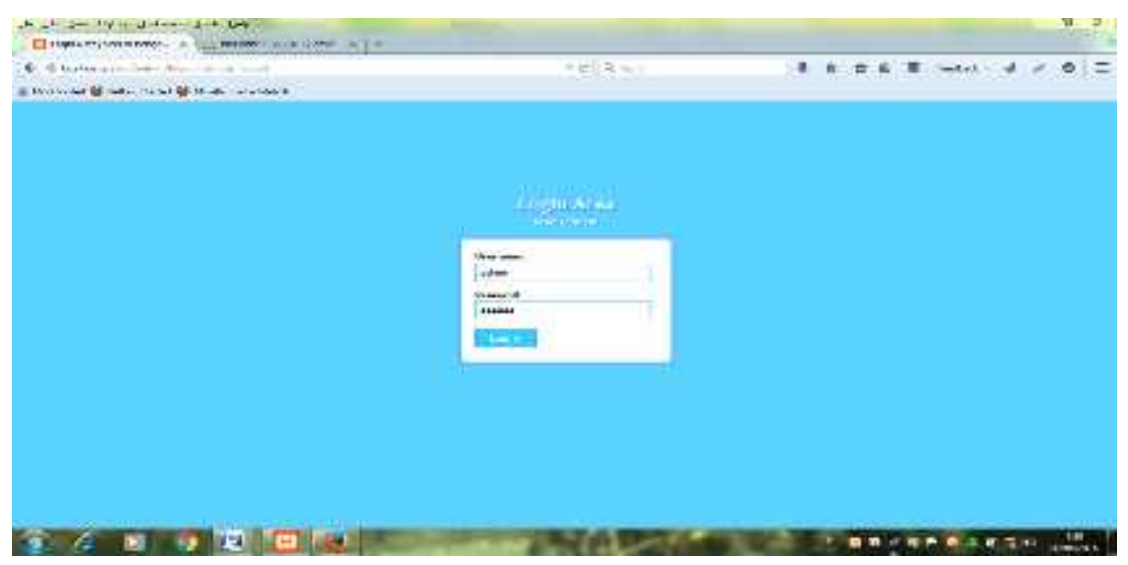

Gambar 2. Impelementasi Menu Login 
Pada tampilan ini menampilkan akses login untuk admin sebagai pengguna sistem penggajian.

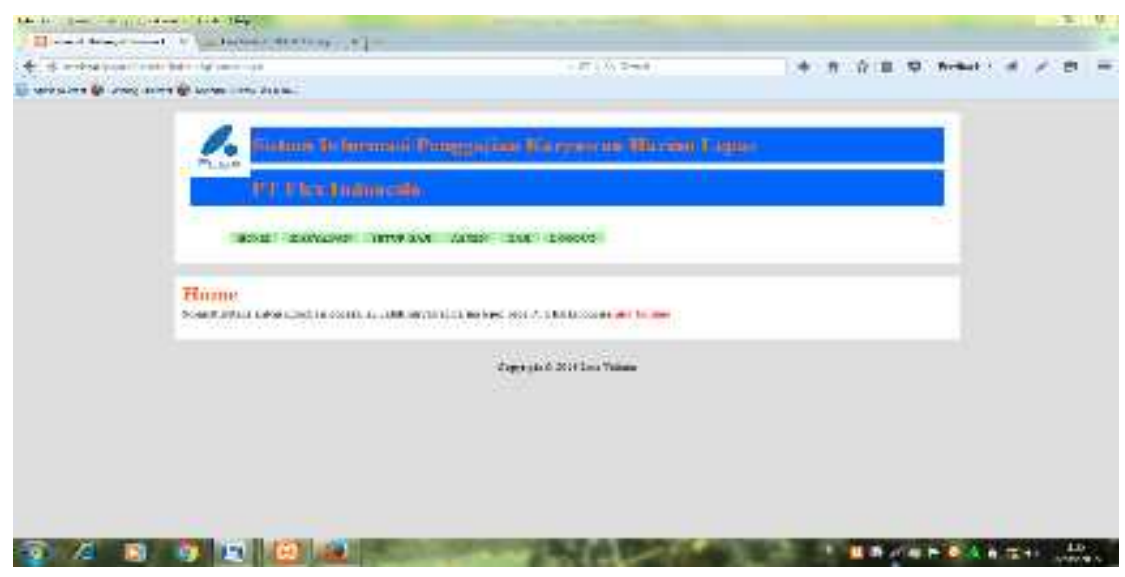

\section{Gambar 3 Implementasi Menu Home}

Pada tampilan ini menampilkan akses login untuk admin sebagai pengguna sistem penggajian.

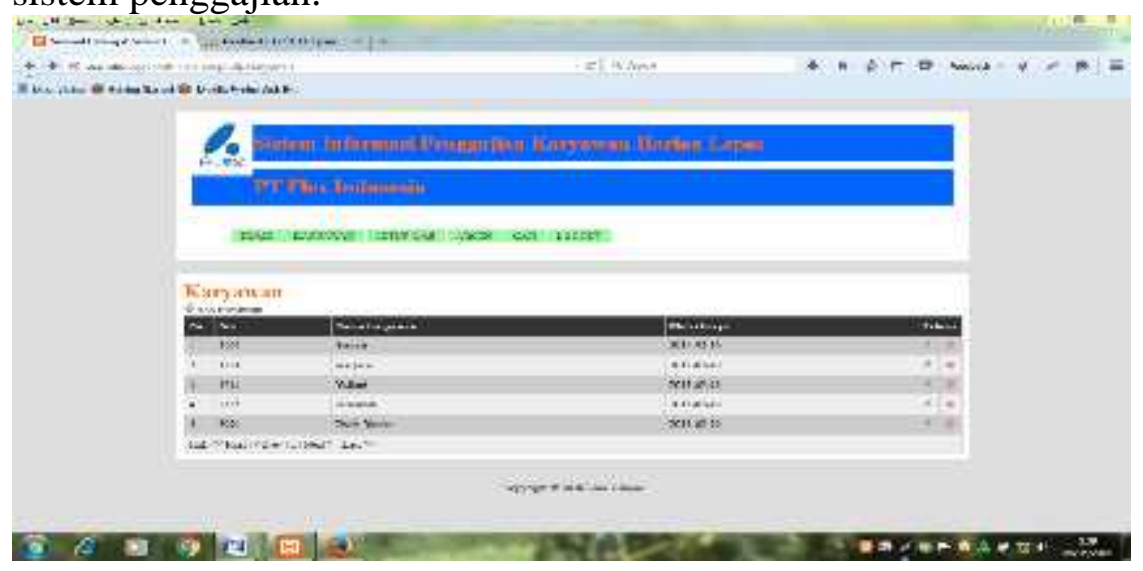

\section{Gambar 4 Implementasi Menu Karyawan}

Pada tampilan ini menampilkan data - data karyawan yang telah di input dan dapat dilakukan edit data dan delete data.

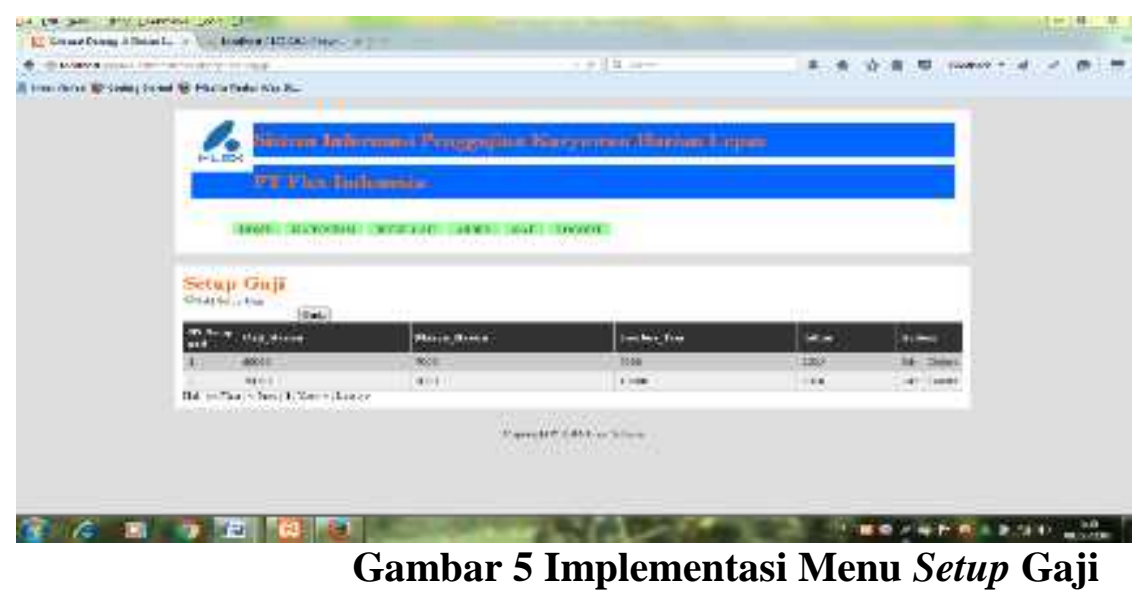


Pada tampilan ini menampilkan data - data ketentuan upah gaji harian , makan harian, lembur per_jam yang telah di input dan dapat dilakukan edit data dan delete data.

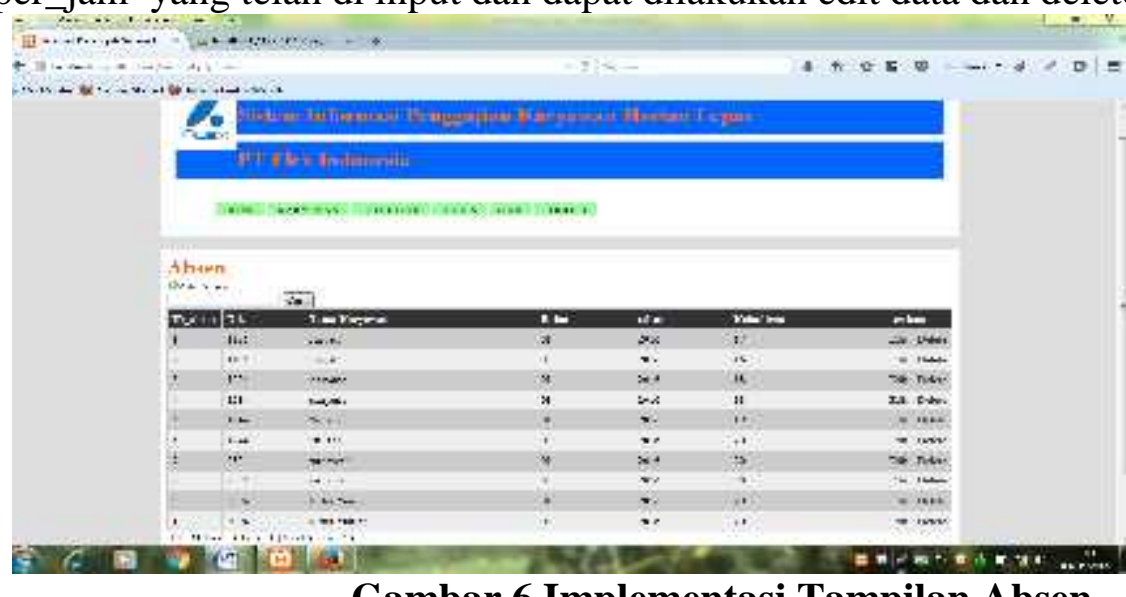

Gambar 6 Implementasi Tampilan Absen

Pada tampilan ini dapat melihat absen harian karyawan yang hadir maupun yang tidak hadir tiap harinya.

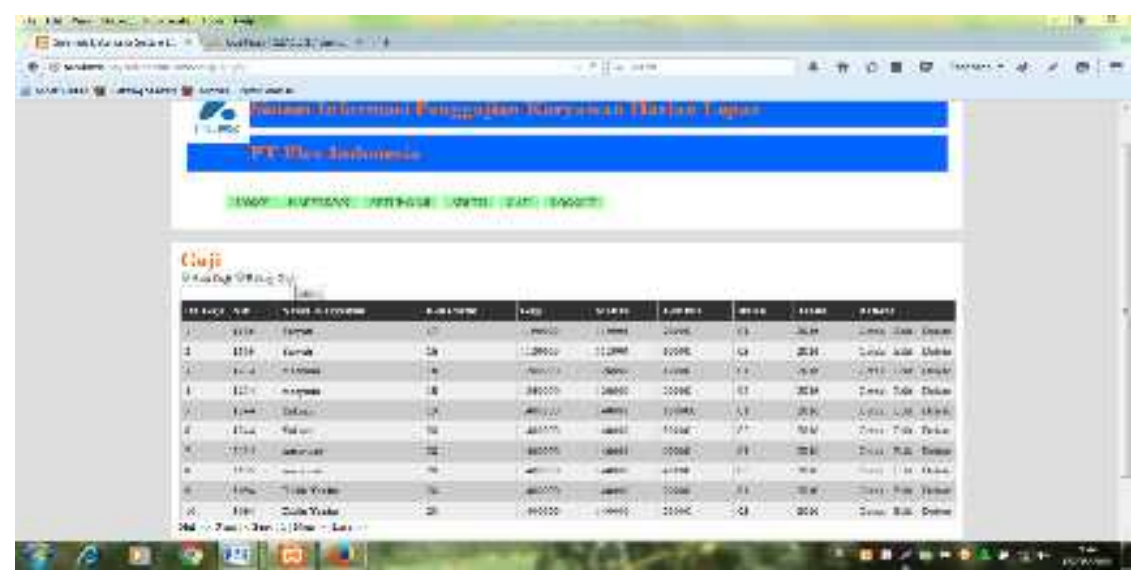

Gambar 7 Implementasi Menu Gaji

Pada tampilan ini menampilkan data - data gaji yang telah di input dan dapat dilakukan edit data dan delete data.

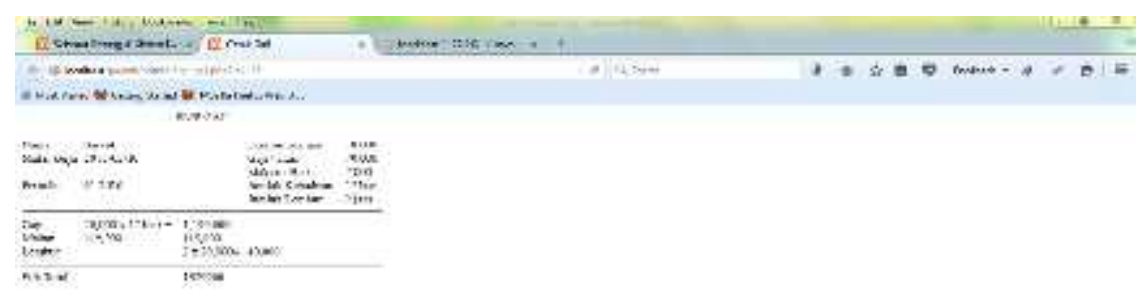

\section{Gambar 8 mplementasi Cetak Slip gaji}

Pada tampilan ini menampilkan hasil perhitungan gaji karyawan yang siap untuk dicetak. 


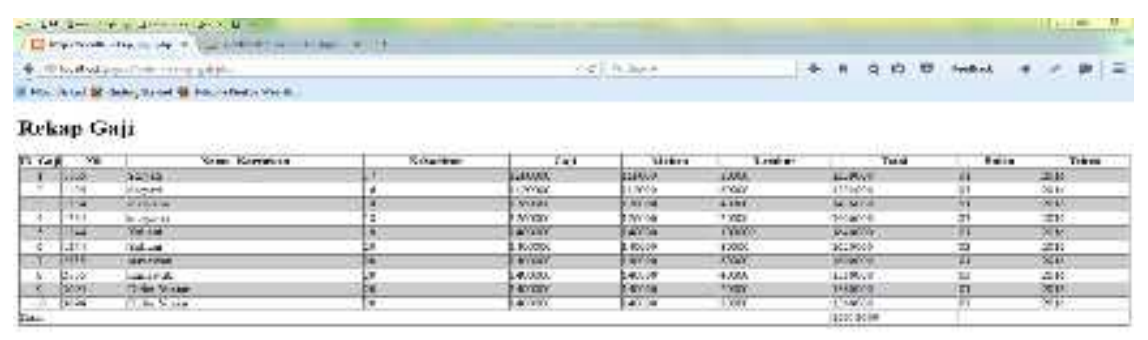

\section{Gambar 9 Implementasi Rekap laporan Gaji}

Pada tampilan ini menampilkan data rekap gaji yang telah di input untuk laporan perhitungan gaji kepada direktur.

\section{KESIMPULAN}

Berdasarkan pembahasan dan hasil penelitian diatas, maka kesimpulan pada penelitian ini adalah sistem informasi penngajian karyawan dirancang menggunakan alat bantu Unified Modeling Languange (UML) dengan software visual paradigm, system dirancang menggunakan MySQL untuk mengelola database dan mampu merekam seluruh data penggajian yang mampu menyajiakan data yang akurat, serta menghasilkan laporan yang tepat waktu sesuai dengan kebutuhan yang diinginkan. Semua data yang berhubungan dengan sistem pembayaran gaji karyawan akan dapat tersimpan dengan baik dan hasilnya akan lebih akurat.PHP adalah bahasa pemograman yang digunakan untuk pembuatan program rancangan yang diusulkan, XAMPP berperan sebagai server web pada komputer dan Drewmweaver CS6 sebagai tools dalam pembuatan program. Rancangan sistem ini dapat meningkatkan kinerja dan efektifitas PT. Flex Indonesia khususnya pada sub bagian Fainance Departement dalam proses penggajian karyawan harian.

\section{DAFTAR PUSTAKA}

[1] Aropah, 2011. "Rancangan Sistem Penggajian Pegawai Honorer Pada SMP NEGERI 2 Gunung Sindur Dengan Metode Berorientasi Object"

[2] Budhi Hartantyo, 2012. "Sistem Informasi Penggajian Karyawan Pada PT.Surya Utama Nusaparka Semarang”.

[3] Chindy Marchelina 2012. "Perancangan Sistem Informasi Penggajian Guru Pada SMP Negeri 1 Mauk-Tangerang”.

[4] Elvi Selviana 2013, "Perancangan Sistem Informasi Penggajian Pegawai Berbasis web pada Kelurahan Cikokol Tangerang".

[5] Sri Indah Sari 2011 "Perancangan Sistem Informasi Penggajian Guru Pada Madrasah Aliyah Al-hasaniyah Tangerang Berbasis Web".

[6] Sugiarti. 2011. "Sistem”, Yogyakarta:Andi Offset.

[7] Sutabri, Tata.2012. "Konsep Sistem Informasi". Yogyakarta:Andi Offset.

[8] Yakub. 2012. "Pengantar Sistem Informasi", Yogyakarta: Graha II. 